\title{
ASPECTOS FILOSÓFICOS E PSICOLÓGICOS DAS PUNIÇÕES: reunindo algumas peças do quebra-cabeça
}

\author{
Noel Struchiner ${ }^{*}$ \\ Pedro H. V. Chrismann **
}

\begin{abstract}
O emprego de sanções é corriqueiro e geralmente associado a uma expectativa de se aumentar a força normativa das regras. Alguns experimentos confirmam essa intuição e indicam que punições fazem com que as pessoas cooperem mais. Filósofos, no entanto, debatem, sem consenso, sobre quais devem ser os propósitos das punições. A despeito da discussão normativa, estudos psicológicos apontam para uma tendência punitiva retributivista no julgamento das pessoas comuns. Além disso, a psicologia tem apontado para algumas assimetrias no comportamento punitivo, como a diferença de preferências na escolha das pessoas na projeção das normas e no seu julgamento; a influência dos juízos morais na atribuição de intencionalidade para os julgamentos punitivos; e certas perplexidades envolvendo punição de acidentes. $\mathrm{O}$ filósofo do direito deveria fazer um esforço para integrar as diferentes informações sobre as punições para fornecer uma explicação mais adequada do fenômeno jurídico e para construir teorias normativas mais factíveis.

PALAVRAS-CHAVE: Sanção. Punição. Filosofia. Psicologia. Direito.
\end{abstract}

\section{INTRODUÇÃO}

Gneezy e Rustichini (2000), no artigo "A Fine is a Price", começam relatando um caso real que funciona como um bom ponto de partida para a discussão de nosso tema: como pensamos sobre sanções e como elas afetam nossas ações. Para nossos propósitos, entenderemos a noção de sanção como a possibilidade de se infligir um mal (punição) a alguém pela não observação de uma regra (Austin, [1832] 2001, p.22). Mais especificamente, analisaremos algumas pesquisas empíricas recentes que dizem respeito às sanções e algumas de suas implicações. O caso diz respeito à regra de uma creche de que os pais não devem se atrasar para buscar seus filhos. No entanto, o diretor dessa creche percebe que, por vezes, os responsáveis

* Professor do Programa de Pós-Graduação em Direito e Filosofia da Pontifícia Universidade Católica do Rio de Janeiro - PUC-Rio. Bolsista de Produtividade em Pesquisa do CNPq. Bolsista Jovem Cientista do Nosso Estado da FAPERJ.

Rua Marquês de São Vicente, 225, Ala Frings, $6^{\circ}$ andar. Cep: 22453-900. Gávea - Rio de Janeiro - Brazil. noel@puc-rio.br

* * Mestrando do Programa de Pós-Graduação em Direito da PUC-Rio. Bolsista FAPERJ. pedrochrismann@gmail.com pelas crianças não respeitam o que foi estabelecido. Tentando diminuir o número de casos de atraso por parte de pais no momento de buscar seus filhos, o diretor estabeleceu uma multa pecuniária para quem, no futuro, viole essa norma. A conduta do diretor parece clara: ele pretende adicionar uma razão a mais para o cumprimento da regra. Ele quer que os pais levem a existência da multa em conta na hora de decidir o que fazer, acreditando que isso irá aumentar a adesão à norma, uma vez que, agora, há a presença de uma ameaça de caráter pecuniário. Ele tenta tornar a regra mais efetiva. Acontece que, ao contrário do que o diretor esperava, o número de casos de atraso sofreu um aumento após a introdução da previsão de multa. Ou seja, mais do que antes - quando não havia tal indicação expressa - mais pais acabaram se atrasando e pagando a multa.

O que se observou foi o fenômeno de enfraquecimento da regra, de perda massiva de adesão ao seu texto, que recebe o nome de efeito de "crowding out" (Sheppard; Cushman, 2009, p. 63) (ou, de "espanta multidão”), exatamente pela ocorrência dessa mudança de postura das pessoas em 
relação à regra após a introdução da sanção. Esse resultado contraintuitivo indica que nem sempre as sanções funcionam da forma como gostaríamos ou como pensamos que elas normalmente o fazem.

São justamente alguns resultados surpreendentes de pesquisas empíricas concernentes às sanções que serão o objeto de nosso estudo. Acreditamos que, por muito tempo, o tema das sanções foi deixado de lado por grande parte dos teóricos e filósofos do direito ${ }^{1}$ e que o tema deveria ser resgatado. Por diferentes motivos, o desinteresse desses estudiosos fez com que o assunto dentro do direito se tornasse quase que exclusivo de matérias como o direito penal e a criminologia. A dogmática penal (e processual penal) costuma exaurir seu trabalho apenas descrevendo quais são as sanções que estão associadas a certos tipos penais e discutindo com o aluno, com base na lei, como funciona a dosimetria das penas, isto é, como se faz o cálculo de atribuição das penas. As abordagens da criminologia, por sua vez, geralmente envolvem investigações descritivas e considerações normativas acerca de políticas de estado que estabelecem punições e o estado atual do cárcere. Há, no entanto, outras formas de estudar o assunto que têm produzido resultados curiosos, com implicações filosóficas significativas. Filósofos experimentais, psicólogos comportamentais e economistas, por exemplo, têm realizado experimentos controlados sobre como funcionam as sanções. Os resultados dessas pesquisas não deveriam ser negligenciados por teóricos e filósofos contemporâneos do direito que pretendem explicar o fenômeno jurídico e fornecer diretrizes para o seu bom funcionamento.

O presente trabalho, preliminarmente, tratará sobre a racionalidade de haver regras e a racionalidade de nelas se incluírem sanções. A

${ }^{1} \mathrm{Na}$ área em que atuamos, a teoria analítica do direito, as sanções foram deixadas de lado depois que H. L. A Hart escreveu The Concept of Law ([1961] 1998). Nesse livro, Hart diz que é concebível um direito sem sanções e que, portanto, sanções não contam como uma propriedade constitutiva e essencial para o conceito de direito. Boa parte dos filósofos após Hart, interessados em fazer investigações sobre as propriedades essenciais do direito, entẫo deixaram de fora de suas agendas a discussão sobre as sanções. seguir, demonstraremos indícios da racionalidade do uso de sanções por meio de relatos de experimentos que fizeram uso de jogos econômicos. Posteriormente, será explicado, em linhas gerais, o debate filosófico normativo sobre as razões corretas que devem justificar a existência de sanções. Essa discussão normativa, no entanto, esbarra no arranjo psicológico de que dispomos e, portanto, serão descritas, em seguida, as conclusões obtidas de experimentos sobre a forma como as pessoas normalmente atribuem punição. Veremos os contrastes entre a discussão filosófico-normativa e as constatações descritivas da psicologia. As descobertas psicológicas também identificam algumas assimetrias relacionadas à nossa capacidade de sancionar. Investigaremos as diferenças entre as escolhas feitas pelas pessoas no momento de projetar normas e suas sanções para o futuro e no momento de aplicar tais normas e suas sanções em situações concretas; como é feita a atribuição de intencionalidade para os julgamentos punitivos; e exploraremos os motivos ligados à punição de acidentes. Por fim, será feita uma conclusão indicando como essas descobertas podem afetar a filosofia do direito e por que elas deveriam ser levadas em conta.

\section{PRELIMINARES SOBRE A RACIONALIDADE DEREGRASESANÇÕES}

Vivemos imersos em ambientes envoltos em regras, sejam elas mais informais, como as que imperam na vida familiar e nos nossos círculos de amizade, ou mais institucionalizadas, como as que encontramos nos nossos locais de estudo, trabalho, e aquelas que regulamentam o espaço jurídico. Nossa vida prática é governada, em larga medida, por regras, e isso faz sentido apesar dos problemas que toda e qualquer regra apresenta justamente pelo fato de ser uma regra. Em outras palavras, regras não são perfeitas. Elas geram resultados insatisfatórios ou não ótimos, mas, mesmo assim, parece ser racional organizar a nossa vida com base nelas. 
A razão de as regras gerarem resultados insatisfatórios em algumas ocasiões, ou pelo menos resultados abaixo da linha do ótimo, é que elas são instanciações generalizadas de considerações normativas mais profundas (Schauer, 1998). Regras simplificam considerações valorativas. Tal simplificação faz com que elas sejam sempre, atual ou potencialmente, sobre ou subinclusivas. Regras são sobreinclusivas ao incorporarem mais casos do que deveriam quando medidas à luz de sua justificação subjacente, e subinclusivas ao deixarem de incorporar casos que seriam englobados por suas justificações subjacentes. ${ }^{2}$

Para tornar tudo isso mais claro, um exemplo pode ajudar: pense em uma regra de trânsito que estabelece um limite de velocidade de $80 \mathrm{~km} /$ $\mathrm{h}$ em determinado trecho de uma rodovia. A justificação dessa regra é proteger a vida. Porém, ao invés de dizer para as pessoas algo como "dirijam de tal forma que as suas vidas e as de terceiros sejam protegidas", ou algo como "dirijam pruden-

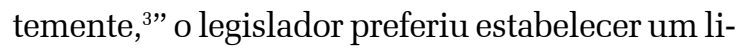
mite de velocidade que deve ser observado por todos, em todos os momentos.

A regra que estabelece o limite de velocidade de $80 \mathrm{~km} / \mathrm{h}$ é, ao mesmo tempo, sobreinclusiva e subinclusiva quando analisada à luz de sua justificação subjacente (proteger a vida). Ela é sobreinclusiva já que, em algumas ocasiões, dirigir acima de $80 \mathrm{~km} / \mathrm{h}$ não representa qualquer tipo de perigo para si e para outros. A rodovia pode estar completamente vazia, o motorista pode ser extremamente habilidoso, as condições do tempo, da manutenção da rodovia e do veículo podem ser excelentes, e, mesmo assim, a regra continua valendo, embora não exista qualquer tipo de ameaça à vida. Uma pessoa parada por um guarda por excesso de velocidade poderia tentar argumentar

\footnotetext{
${ }^{2}$ Sobre a noção de regras como generalizações sobre ou subinclusivas ver Schauer (1998).

${ }^{3}$ Em seu livro, Thinking like a lawyer (2009, p. 16), Schauer diz que, durante um tempo, no estado de Montana, todos os limites de velocidade foram abandonados em troca de uma única diretriz segundo a qual o ato de dirigir deveria ser "razoável e prudente". É claro que isso não funcionou bem, e os limites de velocidade foram reintroduzidos.
}

que é um excelente motorista, nunca bateu antes, seu carro é preparado para atingir uma velocidade de $300 \mathrm{~km} / \mathrm{h}$, o dia está lindo e ninguém mais transitava por lá. Nada disso provavelmente afetaria a atitude do guarda, que simplesmente diria algo como: "Sinto, mas regra é regra". Se, no trecho da rodovia, houvesse um radar, então nem haveria qualquer espaço para discussão. O radar registraria a velocidade, e a multa seria enviada pelo simples fato de o carro estar superando a velocidade permitida. Por outro lado, a mesma regra é, também, subinclusiva, já que, muitas vezes, uma pessoa que dirige muito abaixo da velocidade permitida, ou pouco cuidadosa, ou com defeitos no carro, poderia estar colocando em risco sua própria vida e as de outras pessoas. Mas nada disso é contemplado pela regra. Uma pessoa que dirige abaixo da velocidade não seria parada pelo guarda ou multada pelo radar.

Regras não são perfeitas. Suas aplicações produzem resultados que, às vezes, não são compatíveis com suas justificações subjacentes, mas, mesmo assim, parece fazer sentido organizar nossas vidas por meio delas. Um sistema de regras tem lá suas virtudes e vantagens: pode gerar mais segurança, certeza e previsibilidade do que a convivência que se dá no vácuo de regras. Regras indicam, de antemão, o que é esperado de nós e de terceiros; elas fornecem um mapa com as jogadas possíveis permitidas em sociedade para as quais podemos nos planejar. Além de permitirem mais segurança, certeza e previsibilidade, possibilitam a coordenação entre agentes do mundo prático (por exemplo: imagine o caos que seria se não tivéssemos as regras de trânsito). Regras também produzem eficiência tanto em termos de custos monetários quanto de custos de tempo. Afinal, é muito menos custoso, em termos de tempo e dinheiro, ter um radar que decide quem será multado com base na velocidade, do que contratar especialistas na arte da direção prudente para avaliarem, caso a caso, como as pessoas estão dirigindo. Finalmente, a existência de regras razoáveis, mesmo sendo imperfeitas, pode evitar os chamados custos morais de decisões morais errôneas. Sabemos que 
regras produzem erros de sobre e de subinclusão, mas se acreditamos que menos erros ou erros menos significativos serão produzidos por meio da aplicação de regras do que pela aplicação direta de suas justificações subjacentes, então temos boas razões para adotá-las e para desejar que sejam levadas a sério (Alexander; Sherwin, 2001).

Se fôssemos deuses oniscientes (tanto em questão de fatos quanto em questões valorativas), é provável que as regras não nos seriam úteis ou relevantes. Mas, mesmo anjos bem intencionados, desde que não oniscientes, podem fazer bom uso de regras. Dois anjos podem concordar sobre a necessidade de se fazer o bem, mas podem discordar entre eles sobre a melhor forma de realizá-lo em um caso concreto. Tal discordância pode gerar todos os problemas para os quais as regras aparecem para resolver ou mitigar: falta de certeza, falta de segurança, falta de previsibilidade, falta de coordenação, e os erros originados pela confusão a respeito do significado da justificação subjacente.

Já argumentamos a favor da racionalidade das regras, mas ainda falta sustentar a racionalidade das sanções e das punições. Para tanto, propomos um exercício de pensamento. Podemos, provisoriamente, imaginar que todos somos anjos. Não anjos que vivem no céu com suas asas e harpas, mas anjos naturalistas, isto é, imaginemos que todos nós temos uma inclinação natural para realizar o bem e para evitar ações que causem o mal. Nascemos com um mecanismo inato para fazer o bem. Nesse sentido, teríamos um gosto generalizado pela generosidade. Conforme sugere Cushman (2012), podemos imaginar que fazer o bem, como no caso em que compartilhamos comida com alguém com fome, nos faz sentir bem, enquanto fazer o mal, como quando somos egoístas ou furtamos algo de alguém, nos faz sentir mal. Contudo, podemos conceber uma situação na qual estamos com muita fome, mas sem comida, e a fome é mais forte do que a culpa ou vergonha intrínseca que naturalmente sempre sentimos quando fazemos algo de errado. Nesse caso, a inclusão da sanção poderia ser importante para reforçar a consideração, de forma mais detida, sobre se deveríamos furtar ou não.
Além de nossa inclinação para fazer a coisa certa, ainda teríamos uma razão adicional para se juntar àquela. Mas, tendo em vista que o nosso mundo não contém apenas anjos, que mesmo pessoas bem intencionadas não o são o tempo todo, e que muitas pessoas sequer são bem intencionadas, então a inclusão de sanções e punições para garantir as virtudes e vantagens das regras parece ser uma medida racional.

\section{ALGUNS INDÍCIOS DA RACIONALIDADE DO USO DE SANÇÕES}

Estudos (Fehr; Gächter, 2002; Gürerk et al., 2006; de Quervain et al., 2004), fazendo uso de diferentes jogos econômicos, têm demonstrado que cenários que envolvem punição garantem uma cooperação mais efetiva entre membros de um grupo do que quando não há possibilidade de punição. Esses jogos seguem a mesma lógica do famoso dilema do prisioneiro, em que o melhor resultado possível para um indivíduo envolve uma atitude egoísta, em que ele não coopera, e seus pares agem em prol do grupo. A segunda melhor opção envolve todos cooperarem uns com os outros; uma terceira possibilidade, comparativamente pior que as anteriores, é aquela que não envolve cooperação por parte de ninguém; e o pior cenário é aquele em que só o indivíduo coopera e os outros agem de forma egoísta. O que se observa é que, em cenários em que não há punição, ${ }^{4}$ as pessoas tendem a agir de forma egoísta e buscam sempre o melhor resultado possível para elas, o que acaba gerando um cenário de cooperação muito baixa entre membros de um grupo. No entanto, nos cenários em que há punição, as pessoas tendem a se adequar à opção com a qual todos saem ganhando e que representa a segunda melhor opção individual para cada um, mas a melhor para todos como membros de um grupo.

\footnotetext{
${ }^{4}$ A grande maioria desses jogos foi aplicada em culturas capitalistas do ocidente, e é plausível que esses comportamentos não sejam características universais (Darley,
} 2009, p. 11). 
Em um desses experimentos (Fehr; Gächter, 2002), 240 pessoas participaram do jogo dos "bens públicos". Esse jogo consiste em saber o quanto cada indivíduo investe em projetos de grupo. Cada participante de um grupo formado por quatro pessoas recebia 20 unidades monetárias (UM) e poderia aplicar o quanto quisesse no grupo, sob lucro de 0.4 UM (para cada 1 UM investido) para ele e de 1.6 UM, computada a parte dele, para o grupo, ou seja, para cada unidade monetária investida, cada outro membro do grupo recebia 0.4 UM sem precisar fazer nada. Foram feitas 10 sessões do experimento. Em cada uma delas, 24 participantes jogaram dois jogos por seis períodos: em um dos jogos, não havia possibilidade de punição e, no outro, havia. Nas primeiras cinco sessões do experimento, o jogo sem punição foi jogado antes do jogo com punição; e, nas últimas cinco sessões, o jogo sem punição veio depois. A cada período de sessão, os 24 sujeitos eram randomicamente alocados em seis grupos de quatro pessoas. Ao final de cada período, os participantes eram informados sobre suas próprias decisões, as decisões dos outros membros do grupo e o lucro monetário deles no período corrente (2002, p. 139).

Quando havia a possibilidade de punir aqueles que não cooperavam, essa disponibilidade aparecia após o investimento de cada um ser revelado, e o custo era de $1 \mathrm{UM}$ para quem pune, e de 3 UMs para o punido, podendo-se punir gastando até $10 \mathrm{UM}$. O que foi relatado pelos autores é que, ao final de dez sessões, $84,3 \%$ dos participantes puniram ao menos uma vez; $34,3 \%$ puniram mais do que cinco vezes durante seis períodos; e 9,3\% puniram até mais do que dez vezes. Nas duas sessões, os resultados foram parecidos. Na primeira, em que havia condição de punição e depois passou a não haver, o relato foi no sentido de que, quando havia punição, 38,9\% dos participantes contribuíram com toda sua verba inicial, e $77,8 \%$ contribuíram com ao menos 15 UM, enquanto que, na condição sem punição, $58,9 \%$ não contribuíram com nada, e 75,6\% contribuíram com 5 UM ou menos. (p. 138).

Como dito, parece ser o caso de que, quan- do livres de punição, as pessoas acreditam ser a melhor opção aquela que, em tese, maximiza seus ganhos pessoais. Elas tentam tirar proveito umas das outras para conseguir o maior lucro individual possível. No entanto, várias pessoas pensam assim, e a escolha pela melhor opção racional gera um cenário que promove o resultado da terceira opção, ou seja, aquele em que não há ganhos, ou em que os ganhos são poucos, já que praticamente não ocorre qualquer contribuição significativa por parte dos membros do grupo.

No experimento de Fehr e Gächter descrito acima, ficou demonstrado como a introdução de punições modela o comportamento dos participantes. A ocorrência da punição aumenta a inclinação para a atitude cooperativa dos membros do grupo e, consequentemente, produz uma situação vantajosa para o grupo como um todo. Porém, outra forma de afetar o comportamento das pessoas é dando uma escolha para elas sobre em que grupo querem participar antes e depois de permitir aos membros dos grupos uma análise comparativa dos resultados produzidos por eles. Em um experimento de dinâmica semelhante ao de Fehr e Gächter (Gürerk et al., 2006), foi dada a opção pela escolha entre participar do grupo com punição ou do grupo em que não há punição. A maioria das pessoas escolheu, inicialmente, o segundo grupo. A diferença entre os experimentos é que, nesse, não foi invertida a condição de punibilidade. Ao invés disso, foi dada a possibilidade de os participantes verem o resultado dos grupos durante o jogo e trocarem os grupos que haviam escolhido inicialmente. Ao perceberem que o grupo com a condição de punição estava produzindo um ganho muito maior que o grupo que não dispunha de punição, os membros desse último começaram a migrar para aquele. Ou seja, as pessoas abriram mão racionalmente de um cenário em que não obtinham ganhos significativos, mas em que também não eram punidas, em favor de participarem de um grupo em que devem cooperar, sob pena de serem punidas, para que obtenham lucros consideráveis. Esses experimentos demonstram que, ao menos quando há interesses financeiros em jogo, 
a presença de uma norma social por si só não é capaz de funcionar como uma razão prática forte o suficiente para excluir ou substituir razões de outro tipo. Contudo, quando pessoas punem transgressores, essa possibilidade acaba fazendo com que as normas sejam cumpridas. Se as pessoas fazem cálculo de custo e benefício quando há valores monetários envolvidos, torna-se racionalmente desejável, portanto, incluir sanções financeiras nas regras.

Embora pareça correto, o raciocínio esboçado não está livre de problemas. Há casos em que a presença de multa, por exemplo, faz um trabalho inverso ao esperado, e diminui a cooperação de terceiros em relação às normas. Foi justamente isso que ocorreu no caso da creche (Gneezy; Rustichini, 2000), relatado na introdução. A conclusão de Gneezy e Rustichini (2000), para esse caso, é que, antes de haver uma sanção expressa, a regra era um contrato social incompleto, e as pessoas não sabiam o que esperar da sua violação. Elas não sabiam se deveriam esperar quaisquer sanções, nem de que tipo elas seriam. Teriam seus filhos expulsos da creche? Seriam convocados para uma reunião com a diretora? Encontrariam seus filhos sozinhos do lado de fora do portão? Essa obscuridade garantia certa adesão dos pais. A introdução da multa pecuniária, no entanto, trouxe um preço ao cumprimento da regra. A partir desse momento, as pessoas começaram a se utilizar de cálculos de custo e benefício típicos dos negócios financeiros e, portanto, a decidir se seria custoso ou não, considerando todos os aspectos, deixar de cumprir aquela norma.

Nota-se, portanto, que as sanções exercem, sim, um papel importante para a ação das pessoas. Elas são capazes de mudar o comportamento dos indivíduos e garantir mais cooperação em relação às normas sociais de determinados grupos. Elas o fazem fornecendo um peso a mais a favor da ação prevista pela norma para o raciocínio das pessoas em relação a como elas devem agir. Esse peso é determinado pelo "mal” representado por ela. Um problema é justamente o de escolher a sanção que melhor funcione para cada caso, aque- la que consiga agir no raciocínio prático em favor das regras.

\section{CONTRIBUIÇÕES FILOSÓFICAS: o debate normativo}

Vimos, na parte anterior, por meio dos experimentos descritos, que a introdução de sanções pode trazer boas consequências. Mas, nem todos defendem as sanções em termos de resultados produzidos. Os retributivistas entendem que criminosos devem receber o que merecem por seus crimes. A punição, para Kant, é um imperativo categórico, ou seja, sua imposição independe de seus efeitos serem bons ou ruins; é uma exigência moral derivada dos primeiros princípios ([1798] 2011, p.32). Kant diz ([1887] 2010, p. 198) que, mesmo se a sociedade civil resolvesse se dissolver com o consentimento de todos os seus membros, como no caso de habitantes de uma ilha deserta que resolvem se separar e se espalhar pelo mundo, o último assassino na cadeia deveria ser executado antes que a resolução continuasse. A punição não deve servir para promover um bem para o criminoso ou para a sociedade civil. A ideia do autor é de que a punição deve ser dada ao criminoso apenas por ele ter cometido um crime. As considerações sobre as consequências da punição não interessam a Kant, uma vez que não se deve utilizar uma pessoa como um meio para o propósito de outrem ([1978] 2011, p.31-32).

A ideia de Kant era a de que as pessoas devem ser tratadas da mesma maneira como tratam seus semelhantes. Para o autor, o criminoso não só deve ser punido, como a punição deve guardar proporcionalidade com a ofensa cometida ([1798] 2011, p.32). O retributivismo, portanto, é voltado para o passado, ou seja, o que uma pessoa merece depende especificamente de suas ações passadas.

A corrente utilitarista se diferencia do retributivismo ao pensar para o futuro, nos efeitos que a punição vai gerar. Essa posição remonta às ideias de Bentham ([1822] 2011), que entendia ser o objeto do direito penal aumentar a felicidade to- 
tal da comunidade e excluir, o quanto fosse possível, tudo que tivesse a tendência de diminuir essa felicidade (1822] 2011, p. 51-52). O objetivo é, por vezes, expresso como "atingir o maior bem para o maior número de pessoas” (Tonry, 2011, p. 11). Entretanto, para Bentham, a felicidade de todos inclui a felicidade daqueles causadores de ofensas. O autor entende que toda punição é ruim, representa um prejuízo moral, mas, sob a luz do princípio da utilidade, se ela deve ser admitida, deve apenas enquanto pretender excluir um mal maior ([1822] 2011, p. 63).

A punição, segundo essa visão, deve ser esperada como um peso maior do que os benefícios do crime. A ideia parece ser a de prevenir, ou, ao menos, de reduzir a incidência de tais comportamentos indesejados. Para responder, em linhas gerais, de que forma a punição supostamente deve servir a esse propósito, ao menos três maneiras aparecem: há aqueles que defendem a reabilitação, ou seja, as punições devem reduzir o crime de modo que o punido não se disponha mais a se engajar em uma conduta criminosa; alguns se posicionam a favor da incapacitação, caso em que as punições podem servir para a redução da criminalidade ao tornarem os punidos incapazes de cometerem novamente o mesmo crime; outros acreditam na detenção, e, para eles, as punições devem deter aqueles que, de outra maneira, iriam cometer crimes, servindo como um exemplo. Embora guardem diferenças entre si, como visto, podese agrupar e resumir as ideias das vertentes do utilitarismo da seguinte maneira: o objetivo da punição é aumentar o bem estar do maior número de pessoas; a punição só deve ser admitida quando representar a exclusão de um mal maior para a sociedade; e a punição deve ser moldada de forma a tentar prevenir ou reduzir a incidência de crimes.

Para além da indicação normativa do princípio da utilidade como o guia para o desenho das punições, Bentham faz ainda uma descrição sobre como as pessoas agem ([1822] 2011, p. 53). O autor aposta que o princípio da utilidade é algo que a maioria das pessoas usa na maior parte do tempo, sem nem pensar sobre isso. Ou seja, o autor acre- dita que as intuições das pessoas são utilitaristas a maior parte do tempo. Mas, aqui, Bentham faz uma proposta descritiva e não mais normativa sobre a psicologia da punição. Resta saber se Bentham está correto em sua afirmação, algo que só pode ser verificado empiricamente.

\section{CONTRIBUIÇÕES PSICOLÓGICAS: o debate descritivo}

Como visto, o debate normativo gira em torno de duas posições principais, o utilitarismo e o retributivismo. No entanto, Bentham, defensor do utilitarismo, vai além da esfera normativa e também faz afirmações empíricas e descritivas acerca das intuições psicológicas das pessoas sobre punições. Porém tal tipo de afirmação só pode ser corroborado empiricamente, e os estudos psicológicos demonstram que Bentham estava longe de ter razão nesse ponto.

Com a finalidade de descobrir o que as pessoas levam em conta quando atribuem punição, ou seja, que tipo de informação as pessoas recrutam quando lhes é requerido que tomem uma decisão sobre punição, Carlsmith (2006) montou um experimento em que os participantes deveriam agir como juízes: recomendando uma sentença para um crime que lhes fora descrito. Além do relato do fato, os participantes podiam escolher uma informação adicional sobre aquele crime. O experimentador apresentava diferentes categorias de informação, cada uma unicamente relevante para detenção, incapacitação ou retribuição. Portanto, por exemplo, os participantes podiam escolher categorias de informações como "frequência do crime na sociedade" (uma categoria relacionada à detenção), "possibilidade de repetição" (relacionada à incapacitação), e outras sete possibilidades de informação agrupáveis nas mencionadas teorias. Uma vez escolhida a categoria, o participante ouvia um detalhe particular como "crimes desse tipo são extremamente raros", ou "peritos informaram que o criminoso tende a repetir esse tipo de crime caso lhe seja dada a oportunidade". 
Desse modo, as pessoas poderiam escolher aprender diferentes tipos de informação. A frequência e a ordem de escolha para cada categoria foram as medidas utilizadas pelos experimentadores para entender a preferência das pessoas em relação às perspectivas.

Na primeira de cinco repetições, 97\% dos participantes escolheram uma informação retributiva. Nas segunda e terceira repetições, a grande maioria (64\% e 57\%) também escolheu itens retributivos. Conforme a categoria retributiva ficava sem representantes para a escolha, os participantes passavam a escolher informações da categoria ligada à incapacitação. Apenas quando não havia mais item disponível de outra categoria é que as pessoas escolhiam informações relacionadas à detenção (Carlsmith; Darley, 2008, p.203). Esse experimento revela certa preferência por informações de caráter retributivista na ocasião da atribuição de punição.

Num experimento posterior (Carlsmith, 2006), foi repetida a dinâmica de colocar os participantes na posição de juízes e fornecer uma informação compatível com cada perspectiva, conforme já foi descrito anteriormente. A diferença consistiu em não deixar os participantes escolherem a informação que deveriam receber, mas que lhes fosse atribuída de forma aleatória. Foi, então, pedido a eles que atribuíssem uma punição e informassem o nível de confiança da correção daquela decisão. Não surpreendentemente, as pesso- noso. Foram feitas três rodadas envolvendo manipulações de diferentes fatores de diferentes maneiras em cada uma delas. Ao longo das rodadas, portanto, alterou-se a seriedade da ofensa e a presença de circunstâncias morais como forma de se manipular o fator retributivo; e a dificuldade de se identificar o crime e a publicidade da sentença como forma de se manipular o fator relacionado à detenção. Independentemente da forma como foram feitas as manipulações, as pessoas foram altamente sensíveis às mudanças em fatores retributivos, atribuindo penas mais altas conforme o merecimento e a seriedade do crime; e ignoraram fatores relacionados à perspectiva utilitarista (não havendo qualquer alteração na atribuição de pena nos casos em que houve manipulação para os fatores de detenção). A severidade da punição foi determinada exclusivamente pela manipulação das informações relevantes para o retributivismo.

Nesse estudo, também foram posteriormente medidas as diferenças individuais para saber se havia diferentes tipos de pessoas: aquelas que punem por retribuição e aquelas que punem seguindo um modelo utilitarista. Cada teoria foi explicada, em linhas básicas, para os participantes, e lhes foi demandado que escolhessem o modelo que melhor descrevesse a perspectiva pessoal em relação à punição. Foi descoberto que as pessoas variavam muito em relação a essa questão, e que era fácil dividi-las entre três grupos: retributivistas, utilitaristas e os que possuíam perspectivas mistas. No entanto, de fato, o comportamento das pessoas quase não se diferenciou na hora de punir (Carlsmith; Darley, 2008, p.206). Na prática, todos se mostraram retributivistas.

O procedimento seguinte foi o de se repetir o que havia sido feito no experimento anterior com ligeiras alterações nos casos. Os resultados foram replicados, e houve a inclusão de uma segunda etapa. Nessa parte, 96 de 229 participantes receberam instruções sobre o que seria o retributivismo e o detencionismo, e lhes foi pedido para dar, por mais duas vezes, sentenças para os mesmos casos, só que uma vez pensando como um retributivista e, na outra, como um detencionista. O resultado indi- 
cou que o padrão de atribuição de pena se manteve quando os participantes tiveram de agir como retributivistas, mas houve um aumento nas penas quando puniram seguindo uma postura detencionista (Carlsmith et al., 2002, p. 292). Isso significa que elas estavam sendo retributivistas mesmo antes de lhes ser designada a tarefa de julgar dessa forma, e que elas entendem a postura detencionista como algo que faz com que a quantidade de punição deva ser aumentada para cada caso.

\section{A Assimetria entre projeção e julgamento}

Apesar de esses resultados indicarem uma preferência pelo retributivismo no momento do julgamento, é interessante notar que alguns experimentos mostram que, por vezes, as pessoas têm uma perspectiva diferente quando estão legislando. Carlsmith e Darley (2008) relatam, por exemplo, que algumas pessoas tendem a preferir, quando estão projetando para o futuro, normas com sanções utilitaristas em detrimento daquelas com sanções retributivistas, ou seja, punições justificadas com o objetivo de se evitarem novas condutas, ao invés de punições proporcionais ao ato em si. No entanto, quando devem aplicar essas mesmas normas criadas por elas, as pessoas tendem a buscar motivos retributivistas e não mais endossam o texto que haviam aceitado.

Para comprovar isso, Carlsmith et al. (2002) realizaram outro experimento. Foi dada uma tarefa de alocação para os participantes. Eles deveriam sugerir que fossem alocados os recursos da cidade para capturar criminosos (uma ação consistente com uma perspectiva retributivista) ou para prevenir crimes futuros desse mesmo tipo (uma ação relacionada ao utilitarismo). Foi descoberto que as pessoas demonstram uma grande preocupação em prevenir futuras ocorrências do crime, mas que esse desejo não está relacionado com os detalhes do crime. Os participantes recomendaram maior alocação em prevenção de futuros crimes do que em capturar criminosos, demonstrando estar de acordo com uma posição utilitarista. Portanto, ape- sar de endossarem objetivos ligados a teorias utilitaristas (prevenir novos crimes) enquanto projetam as normas, quando na posição de julgadoras, as pessoas não punem de forma a concretizá-las. Afinal, conforme visto nos outros experimentos, ficou demonstrado que elas se utilizam mais frequentemente de critérios retributivistas e se sentem mais confortáveis dessa forma (Carlsmith et al., 2002, p. 295).

Um exemplo real dessa discrepância em normas jurídicas é o da lei de " 3 strikes" da Califórnia. Tratava-se de lei que exigia que o governo sentenciasse à prisão perpétua aqueles que fossem reincidentes após dois ou mais "crimes sérios" (felonies). Tal norma foi aceita e promulgada por 70\% da população em referendo estadual. O que os cidadãos da Califórnia não esperavam é que essa norma seria incompatível com sua perspectiva retributivista. Quando em vigor, alguns casos bizarros, em que o último "crime sério" era de menor potencial lesivo (minor felony), começaram a aparecer. Jerry Dewayne Williams foi condenado à prisão por 25 anos pelo furto de um pedaço extragrande de pizza sabor pepperoni ${ }^{5}$. Santos Reyes foi condenado a 26 anos, no terceiro strike, por perjúrio, uma vez que ele fez, no lugar de seu primo, que sabia dirigir, mas não sabia ler, a parte escrita do teste para a licença de motorista, para ajudá-lo a passar na prova. ${ }^{6}$ Kevin Weber pegou 25 anos por invadir um restaurante e furtar cookies de chocolate. ${ }^{7}$ Após ver essa lei em ação e esses resultados aparecerem, em poucos anos as pesquisas (Carlsmith; Darley, 2008, p. 208) mostraram que o apoio à lei já era menor do que 50\% na população.

Um experimento de Carlsmith (2008) tentou repetir esse fenômeno. Foi descrito aos participantes o problema que as escolas têm tido com estudantes usuários de drogas e apresentadas diferentes políticas a serem adotadas para o problema.

${ }^{5}$ http://articles.latimes.com/2010/feb/10/local/la-mepizzathief10-2010feb10

${ }^{6} \mathrm{~h} \mathrm{t} \mathrm{t} \mathrm{p} \mathrm{://} \mathrm{s} \mathrm{o} \mathrm{cialis} \mathrm{tworker.org/2005-1/542/}$ 542_05_SantosReyes.shtml 7 http://edition.cnn.com/US/Newsbriefs/9510/10-27/ 
Apesar de a maioria ter preferido respostas proporcionais às ofensas, numa perspectiva retributivista, uma minoria substancial (30\%) apoiou uma política de tolerância zero, baseada na teoria utilitarista. Posteriormente, foi descrito um caso em que uma menina era encontrada no banheiro com remédios não prescritos, considerados como drogas para os efeitos legais, e questionado se as pessoas mantinham o que haviam entendido ser a política correta. Quando os participantes que apoiaram a política da tolerância zero descobriram que ela violava a proporcionalidade, e, portanto, seus sensos intuitivos de igualdade, o apoio a essas políticas caiu para apenas 6\%.

Esse estudo concluiu que "as pessoas têm uma introspecção apenas limitada às razões para suas punições, e essa ignorância pode levá-las a endossar políticas que, ironicamente, irão logo rejeitar como desiguais e injustas" (Carlsmith; Darley, 2008, p. 208). A conclusão dos autores é de que as pessoas não têm completa consciência sobre as razões que as levam a punir outras. Elas são retributivistas, mas talvez não o percebam. Quando estão pensando em punições futuras, não têm diante de si uma transgressão já existente e, portanto, seus julgamentos reais não são acionados. Assim, a assimetria entre nossa psicologia retributivista de julgamento e utilitarista de projeção indica um dos motivos pelos quais podemos ter a sensação de que uma norma é injusta. Se tivermos distintas noções sobre punição justa conforme a posição que ocupamos (juiz ou legislador), ficará difícil dar uma resposta teórica que satisfaça todos os casos.

\section{A assimetria na atribuição de intencionalidade}

Vimos, acima, uma série de experimentos que, conjuntamente, corroboram que a psicologia descritiva das pessoas no momento de julgar a ação de outra e resolver se uma punição deve ser atribuída é retributivista. Conforme diz Cushman (2012), o caminho rotineiro para a atribuição de punição segue o seguinte trajeto: quando algo de ruim acontece, procuramos saber se alguém foi o agente causal do resultado ruim ou do dano produzido; em caso positivo (se a causa é um agente humano e não a natureza), procuramos saber sobre o estado mental do agente no momento da ação, isto é, se ele tinha a intenção de realizar o ato sob discussão ou produzir os resultados da ação; por último, formamos um julgamento atributivo de punição proporcional ao mal causado e ao grau de culpabilidade do estado mental. Assim, temos o vínculo entre retributivismo e estado mental. Se o retributivismo sustenta que as pessoas devem ser punidas quando são merecedoras, então parece que o principal elemento constitutivo desse merecimento é o estado mental do agente, que, por sua vez, tem como seu principal elemento constitutivo a intencionalidade.

Sendo assim, cabe discutir, também, alguns achados intrigantes sobre como atribuímos intencionalidade. O filósofo Joshua Knobe, um dos expoentes do novo movimento conhecido como "filosofia experimental”, constatou assimetrias interessantes na forma como atribuímos intencionalidade para certos atos. Em um experimento que ganhou muita repercussão nos âmbitos da psicologia, da filosofia moral e da filosofia da ação, Knobe mostrou que a nossa atribuição de intencionalidade para ações que produzem certos efeitos colaterais depende de nossa avaliação moral prévia dos resultados da ação. São nossas considerações morais sobre os efeitos colaterais que determinam nossa atribuição de intencionalidade. Vejamos os cenários do experimento que foi utilizado para se chegar a tal conclusão:

(A) $\mathrm{O}$ vice-presidente de uma empresa foi falar com o presidente do conselho e disse: "Estamos pensando em começar um novo programa. Ele nos ajudará a aumentar os lucros, mas vai também prejudicar o meio ambiente".

O presidente respondeu: "Eu não me importo nem um pouco com os prejuízos ao meio ambiente. Apenas quero lucrar o máximo que for possível. Vamos iniciar o novo programa". Eles começaram o novo programa. Evidentemente, o meio ambiente foi prejudicado.

(B) $\mathrm{O}$ vice-presidente de uma empresa foi falar com o presidente do conselho e disse: "Estamos pensando em começar um novo programa. Ele 
nos ajudará a aumentar os lucros, mas vai também beneficiar o meio ambiente".

O presidente respondeu: "Eu não me importo nem um pouco com os benefícios ao meio ambiente. Apenas quero lucrar o máximo que for possível. Vamos iniciar o novo programa" (Knobe, 2003).

Eles começaram o novo programa. Evidentemente, o meio ambiente foi beneficiado.

Depois de apresentar a primeira vinheta para um grupo de pessoas, Knobe perguntou para elas o quão culpado era o presidente (em uma escala de 0 a 6) por ter causado o dano ao meio ambiente, e se o presidente teria causado o dano intencionalmente (a pessoa deveria indicar sim ou não como resposta). Nesse caso, 82\% dos participantes responderam que o presidente havia prejudicado o meio ambiente intencionalmente. Por outro lado, apenas $23 \%$ das pessoas que receberam a segunda vinheta responderam que o presidente teria beneficiado o meio ambiente intencionalmente. O curioso, como se pode notar ao ler os diferentes cenários, foi que o presidente da empresa disse a mesma coisa em ambas as vinhetas, isto é, que não se importava nem um pouco com o meio ambiente, mas apenas com os lucros da empresa. A conclusão é a de que, no caso em que o efeito colateral é considerado moralmente ruim, as pessoas costumam atribuir intencionalidade, enquanto nos casos em que o efeito colateral é considerado moralmente adequado, as pessoas não costumam atribuir intencionalidade.

A assimetria descrita acima ficou conhecida como "efeito do efeito colateral" (side-effect effect) ou "efeito Knobe" (Knobe effect), pelos estudiosos que começaram a escrever sobre o assunto após a descoberta de Joshua Knobe. A assimetria chama a atenção porque, normalmente, pensamos que os nossos julgamentos morais adotam um percurso unidirecional no qual primeiro acessamos a intencionalidade de alguém, para depois decidir sobre sua responsabilidade moral. Achamos que a noção de intencionalidade é sempre moralmente neutra, que se trata de um conceito de nossa psicologia do senso comum e que ela sempre funciona como um precursor dos juízos morais: se a ação é intencional, então podemos, posteriormente, fazer uma avaliação genuinamente moral. Contudo, os estudos de Knobe demonstram que o caminho entre intencionalidade e julgamento moral é, na verdade, bidirecional. Muitas vezes, analisamos a intencionalidade avaliando estritamente o estado mental das pessoas, mas, em outros casos, atribuímos intencionalidade justamente depois que fazemos uma avaliação moral dos resultados. Se os resultados desagradam do ponto de vista moral, então atribuímos intencionalidade (Knobe, 2009). ${ }^{8}$ As implicações dessa discussão para o direito são significativas. Os sistemas penais costumam distinguir entre crimes dolosos e crimes não dolosos. O dolo requer que a ação realizada tenha sido intencional. Isso quer dizer que um crime só deveria ser caracterizado como doloso depois da avaliação sobre a intencionalidade do ato sob julgamento. A intencionalidade deveria ser avaliada de forma neutra e imparcial. No entanto, como foi demonstrado, por vezes, as avaliações morais interferem em nossos juízos de atribuição de intencionalidade. No direito penal, lida-se com situações que produzem resultados considerados ruins do ponto de vista moral. Sendo assim, é provável que, por terem avaliado os efeitos da ação como indesejados ou perniciosos do ponto de vista moral, os juízes e jurados tenham sempre uma inclinação para tratar as ações (pelo menos aquelas que provocam efeitos colaterais moralmente perniciosos) como intencionais e qualificar os crimes como dolosos.

\section{Punindo acidentes}

Como vimos, nossas intuições punitivas são, na maior parte das vezes e para a maior parte das pessoas, retributivistas. Logo, punimos com base no que o transgressor da norma merece. Esse merecimento parece exigir uma leitura do estado men-

${ }^{8}$ Knobe acredita que não é só o conceito de intencionalidade que é afetado pela moralidade. Outros conceitos psicológicos, como desejo, crenças, e até conceitos não psicológicos, como o de causalidade, também sofrem o impacto da avaliação moral e podem apresentar assimetrias em seus usos, em certos casos (2009). 
tal do transgressor. Isso fica muito claro quando imaginamos um cenário no qual duas pessoas realizam o mesmo ato, ambas produzindo um resultado danoso para um terceiro. Se uma delas intencionalmente causou o resultado, enquanto a outra não o fez, punimos mais severamente o ato que foi realizado intencionalmente. No entanto, ainda que a intencionalidade exerça um papel importante nos nossos julgamentos sobre punição, isso não quer dizer que resultados não intencionais estejam sempre livres de punição. Não é totalmente incomum punirmos, de alguma forma, aqueles que nos prejudicam acidentalmente, e a maior parte dos sistemas jurídicos vislumbram alguma possibilidade de punição para atos acidentais.

Em um experimento (Cushman et al., 2009) envolvendo um jogo econômico probabilístico, apelidado de jogo da "mão trêmula", um jogador deveria alocar dinheiro entre ele e um parceiro. Ele poderia fazer isso ou de forma egoísta (tudo para ele), ou de forma equânime (metade para cada um), ou generosamente (tudo para o parceiro). Porém a alocação não era feita diretamente, mas era mediada pelo lançamento de um dado. Se o alocador quisesse ser egoísta, ele então escolhia um dado (dado A), que tinha 4/6 de chances, quando lançado, de dar o resultado egoísta. Se, ao ser lançado, a face superior do dado mostrasse 1, 2, 3 ou 4, o alocador ficaria com todo o dinheiro, mas se mostrasse 5 , então o dinheiro seria dividido entre o jogador e o parceiro, e se o dado mostrasse 6, então todo o dinheiro iria para o parceiro. Caso o alocador quisesse ser justo na distribuição, ele escolheria outro dado (dado B), que apresentava 4/6 de chance de gerar como resultado a distribuição igualitária, mas $1 / 6$ de chance de gerar o resultado egoísta e 1/6 de chance de gerar o resultado generoso. Se ele quisesse ser generoso, então escolheria um dado (C) que apresentava $4 / 6$ de chance de gerar o resultado generoso, mas 1/6 de chance para cada uma das outras possibilidades. Assim, o jogador poderia ter uma intenção egoísta, mas uma alocação generosa; uma intenção equânime e uma alocação egoísta; e todos os outros arranjos possíveis. O parceiro, por sua vez, depois de ver a escolha do dado e o resultado de seu lançamento, tinha a chance de responder aumentando, ou seja, recompensando-o, ou diminuindo o pagamento do alocador, punindo-o. Os participantes puniram tanto intenções avarentas como resultados avarentos acidentais (Cushman, 2012, p. 10).

A resposta para esse comportamento, sugere Cushman (p. 10), pode ser a de que punimos acidentes porque isso teria uma função pedagógica, trazendo benefícios utilitaristas medidos em termos de comportamentos pró-sociais. Podemos, no entanto, não estar totalmente conscientes dessa função quando punimos os acidentes. Talvez estejamos punindo porque achamos que a pessoa que deu origem ao resultado ruim provocado pelo acidente merece ser punida, independentemente dos benefícios que isso poderia trazer para o próprio transgressor ou para as pessoas que vivem na mesma comunidade. Nesse caso, as punições ainda seriam fruto de uma espécie de psicologia retributivista, já que não estaria baseada nas consequências da punição, mas seria um retributivismo que nem sempre leva em conta a intencionalidade na configuração de merecimento. De qualquer forma, independentemente da psicologia descritiva que subjaz à punição de acidentes, ainda assim permanece a questão sobre se Cushman teria razão sobre sua função pedagógica.

O acidente pode representar um momento de ensino de limites (territoriais, de propriedade ou relacionais) ou um alerta para que aquela pessoa tenha mais cuidado no futuro ao realizar aquela ação. Para esse alerta funcionar, supõe-se que a pessoa que cometeu o acidente deveria ter algum controle da situação, e parece que isso é levado em conta pelo julgador. Há evidência experimental que sugere punirmos acidentes apenas quando os comportamentos poderiam ser controlados (Alicke, 2000; Cushman et al., 2009). No jogo da "mão trêmula", quando o alocador tinha algum controle probabilístico pela alocação ao escolher um de três dados disponíveis, ele era punido pelo acidente, como foi descrito. No entanto, quando o alocador não tinha qualquer controle probabilístico sobre a alocação - quando ele era forçado a rolar um único 
dado onde resultados egoístas, generosos ou equânimes eram igualmente prováveis - ele era punido menos, e, às vezes, nem era punido pelos resultados acidentais (Cushman, 2012, p. 10).

Esse foco na possibilidade de controlar o resultado faz sentido de uma perspectiva funcional, que visa a modificar o comportamento futuro de parceiros sociais. Não há valor em ensinar uma lição para alguém que não tinha como ter controle da situação e, portanto, não tem como modificar seu comportamento no futuro. Para funcionar, portanto, o transgressor deve ser capaz de aprender a lição que se está querendo passar com a punição. Mas, de que forma as pessoas punidas aprendem? De maneira a não fazer aquele ato de novo, ou a não causar aquele resultado de novo? A questão é se nosso mecanismo de aprendizagem associa a recompensa ou a punição à ação intencional ou, ao invés, ao resultado que foi produzido.

Um experimento (2012, p. 11), com uma versão modificada do jogo da "mão trêmula", tentou iluminar essa questão. Nesse jogo, um jogador atirava dardos em um alvo multicolorido, e seus acertos faziam com que um segundo jogador perdesse ou ganhasse dinheiro. Quem atirava não sabia qual a diferença das cores, ou o que faria com que seu parceiro perdesse ou ganhasse dinheiro. Seu parceiro, entretanto, podia ensinar o jogo, recompensando-o ou punindo-o a cada tiro. $\mathrm{O}$ atirador devia dizer onde iria acertar antes de arremessar o dardo, e toda vez que ele acertava a cor que dizia, ele recebia um bônus do experimentador. Assim, ele tinha um incentivo claro para ser honesto sobre o que ele estava mirando. O parceiro sabia, portanto, onde o atirador acertava o dardo e qual era a sua intenção.

Os resultados mostraram que o atirador aprendeu melhor o valor dos alvos quando o parceiro adotava uma estratégia de punição baseada no resultado, e não na intenção (Cushman, 2012, p. 11). Isso indica que há, portanto, vantagens em se punir resultados acidentais em certas circunstâncias, devido à estrutura do processo de aprendizagem humana, que parece associar, de forma mais satisfatória, os estímulos de recompensa ou punição ligados ao resultado do que aqueles ligados à sua intenção.

Embora nossas motivações psicológicas sejam basicamente retributivas e não estejamos preocupados com as consequências, elas podem produzir efeitos de detenção ou incapacitação. "A punição pode ser adaptativa para razões detencionistas em um 'último' nível adaptativo, e ainda assim serem instanciadas por mecanismos retributivos em um nível adaptativo 'próximo"” (2012, p. 9). Talvez essa intuição retributiva traga com ela a solução para o problema de como garantir pró-sociabilidade de seus parceiros sociais no futuro, e isso seja algo bom. Talvez pensar em todos os casos de forma utilitarista sobre os benefícios futuros da pena demande tempo e acabe gerando mais erros. Cushman (p.9) usa uma metáfora ilustrativa: consumimos açúcar e gordura pelo gosto agradável, e não por causa de um aprendizado acerca da associação deles ao fornecimento de energia. Ter um gosto inato por esses produtos resolve o problema de se ter de aprender, por associação, quais as propriedades de possíveis alimentos estão ligadas ao fornecimento de energia. Parece que nosso gosto por punição acaba resolvendo o problema da necessidade de se ensinar que as pessoas devem cooperar e o problema de ter de ficar refletindo, a cada momento, sobre o mecanismo que vai possibilitar tal cooperação.

\section{CONCLUSÃO}

A discussão sobre sanções e punições está repleta de polêmicas, tanto descritivas quanto normativas. As punições parecem ser ferramentas racionais para garantir as consequências benéficas de um sistema de regras. A noção de estado de direito (rule of law) destaca, desde suas versões mais básicas até suas versões mais sofisticadas (Fuller, 1969; Tamanaha, 2004), a importância de se viver em um ambiente de regras, e não em um ambiente onde as decisões são tomadas de forma ad hoc, seguindo os caprichos do responsável de plantão. Regras devem ser razoáveis de forma tal 
que possam trazer virtudes como segurança, certeza, previsibilidade, coordenação, eficiência, prevenção de erros, entre outras. Mas é claro que nem todos concordam sobre o grau em que o direito deve se manifestar por meio de regras, nem sobre quais devem ser os conteúdos das regras. Mas, seja lá como for, com menos regras ou mais regras, com regras de conteúdo mais próximo de uma ideologia ou de outra, o ponto é que nem todos seguem as regras adotadas; não vivemos em uma sociedade de anjos. Para aqueles que não internalizam as regras por si mesmas como razões para agir, podese usar um mecanismo para garantir que os cursos de ação adotados sejam compatíveis com o conteúdo das regras: sanções e punições.

Vimos que a introdução da punição em jogos econômicos tende a aumentar a cooperação entre as pessoas e trazer vantagens. No entanto, como nos ensina o caso da creche, citado na introdução, as sanções e suas punições correspondentes devem ser calibradas de forma adequada, sob pena de produzirem um resultado indesejado. Mas é polêmico se outros métodos poderiam fazer o mesmo papel das sanções, com o mesmo índice de sucesso, mas de forma menos agressiva. A verdade é que nem todos consideram punições justificadas, como nos mostra a tendência do abolicionismo penal. Na filosofia, entre os que aceitam a punição de peito aberto, existe grande discordância sobre o que faz com que uma punição esteja justificada do ponto de vista normativo. Nesse campo, o principal embate se dá entre utilitaristas e retributivistas. Os retributivistas acreditam que se deve punir para se fazer justiça, de forma a dar ao transgressor de uma norma o que ele merece por seu ato. Os utilitaristas, por outro lado, acreditam que as punições devem aumentar a pró-sociabilidade dos membros de uma comunidade para que isso traga benefícios para todos.

Para além das pretensões normativas das duas correntes, a psicologia tem demonstrado, por meio de experimentos, que as pessoas são, em geral, retributivistas, quando atribuem punição. Essa conclusão, no entanto, não é tão simples, e mostramos que algumas assimetrias surgem a partir dela: as pessoas parecem usar perspectivas diferentes quando projetam normas do que quando as aplicam; a atribuição de intencionalidade a um ato não está livre da sua avaliação moral, como imaginamos. E, embora a intencionalidade tenha um papel importante no nosso julgamento sobre atribuição de punição, às vezes avaliamos também o resultado, uma vez que punimos acidentes.

Poderíamos enumerar várias outras discordâncias e discrepâncias significativas que ocorrem no âmbito da discussão sobre as sanções e punições. Mas, apesar de todas essas polêmicas científicas e filosóficas, existe um ponto em relação ao qual todos concordam: punição é assunto sério! A ideia de aceitar ter um terceiro se imiscuindo em sua vida por meio de força e influenciando a sua conduta por meio de ameaças de punições não é facilmente digerida. Sendo assim, esperaríamos que o assunto fosse levado a sério sempre, principalmente por juízes de direito. Independentemente da posição específica de um juiz específico, ele deveria sempre ter a maior seriedade possível ao lidar com questões que envolvem sanções e punições.

Contudo, um estudo recente realizado em Israel revelou resultados sombrios e desanimadores. Shai Danziger, Jonathan Levav e Liora AvnaimPesso (2011) fizeram uma pesquisa cuidadosa com o objetivo de entender como juízes decidem em casos em que presos requerem livramento condicional ou outras melhorias em suas condições prisionais. Eles pegaram dados de 1.112 audiências judiciais presididas por 8 juízes diferentes, que possuíam uma média de 22 anos de experiência no exercício da função. $\mathrm{O}$ que os pesquisadores descobriram, ao controlar diversos fatores (jurídicos e não jurídicos) que poderiam afetar a decisão dos juízes, foi estarrecedor: o fator que melhor explicava as decisões dos juízes era a proximidade da decisão à hora do intervalo!

O dia dos juízes continha dois intervalos, um para o lanche da manhã, e outro para o almoço, fazendo com que os julgamentos acontecessem em 3 diferentes sessões. Assim que começava o dia, aproximadamente $65 \%$ dos pleitos eram con- 
cedidos, mas esse índice decaía de forma dramática, chegando a $0 \%$ de concessão para os pedidos próximos ao primeiro intervalo para o lanche. Logo após o primeiro intervalo, o índice de acolhimento dos pedidos voltava para a casa dos $65 \%$, caindo para $10 \%$ próximo ao segundo intervalo para o almoço. Depois do almoço, novamente as concessões voltavam ao índice de $65 \%$, para, logo depois, caírem vertiginosamente mais uma vez. A conclusão dos autores é de que o destino do preso depende principalmente de um fator meramente contingente, isto é, do momento em que o seu caso é julgado.

Segundo os pesquisadores, a fadiga mental dos juízes faz com que adotem a posição default de manutenção do status quo, o que significa a preservação das condições prisionais do preso. As decisões que rejeitavam as solicitações e preservavam as condições prisionais continham menos palavras, e as audiências eram mais curtas, e, sendo assim, exigiam menos dos juízes. A fadiga mental pode ser gerada por três causas diferentes, que podem trabalhar de forma independente ou em conjunto: a quantidade de decisões que vai usurpando a energia mental do agente decisório; a fome e a necessidade de repor o nível de glicose do organismo; e também o mau humor, que pode aumentar com a fome e o cansaço. Como os autores não utilizaram qualquer medida para avaliar essas três possibilidades, a questão ficou em aberto, mas uma coisa é certa: juízes decidem de forma muito diferente antes do intervalo e depois de um intervalo para comer.

O filósofo do direito deve levar todas essas informações em conta para construir a sua teoria descritiva e normativa sobre o direito. A explicação sobre as sanções (e as punições que incorporam), que constituem um componente tão marcante dos sistemas jurídicos existentes, não pode ser feita superficialmente. Mas, principalmente, se filósofos pretendem construir teorias normativas com implicações práticas, então não podem negligenciar as descobertas dos estudos empíricos, principalmente os psicológicos. Ainda que os resultados dos experimentos apresentados aqui não se- jam totalmente conclusivos, parece interessante investir nesse tipo de abordagem, já que os estudos empíricos fornecem o espaço de possibilidades para um desenho institucional viável. Afinal, não adianta ter em mente uma teoria normativa preferida sobre as punições e achar que, com isso, todos os problemas estão resolvidos. Também se faz necessário avaliar em que medida a psicologia descritiva das pessoas é compatível com tal teoria e todas as dificuldades que devem ser enfrentadas na sua implementação. Algumas pessoas defendem teorias normativas utilitaristas da punição, mas em que medida elas são compatíveis com nossas intuições retributivistas no momento de punir? E como lidar com o fato de que elementos extrínsecos a qualquer consideração sobre a punição, como a fadiga mental do julgador, podem afetar a sua atribuição?

O filósofo do direito não pode, portanto, abrir mão de uma abordagem interdisciplinar e empírica. Para poder prescrever adequadamente, é fundamental conhecer a estrutura e a arquitetura cognitiva (racional e emotiva) dos agentes destinatários das prescrições: nós mesmos. Se não levamos em consideração como efetivamente tomamos as nossas decisões e nos comportamos, o risco é construir uma teoria normativa do direito baseada em uma psicologia moral equivocada e alijada da prática. Dessa forma, é salutar sempre manter em mente, ao construir uma teoria normativa ou sugerir reformas institucionais, o "Princípio do Realismo Psicológico Mínimo” de Owen Flanagan, ao dizer que devemos "ter certeza, quando construindo uma teoria moral ou projetando um ideal moral, que o caráter, o processamento da decisão e o comportamento prescrito são possíveis, ou percebidos como possíveis, para criaturas como nós." (Flanagan, 1991, p. 32). Afinal, a que propósito servem teorias normativas que ninguém pode aplicar?

Além disso, vários teóricos da punição trabalham dentro de seus nichos específicos e, portanto, parece que cabe ao filósofo a função de integrar, de forma rigorosa e cuidadosa, tantas informações sobre as sanções produzidas por tantas áreas e métodos de investigação diferentes. Tudo 
que nós fizemos aqui foi encontrar algumas poucas peças do quebra-cabeça da sanção ou punição que estavam espalhadas por aí, mas ainda estamos longe de saber montá-lo. Ficaremos satisfeitos, mesmo se estivermos errados nas poucas tentativas de juntar algumas das peças, se esse esforço servir, ao menos, como incentivo para que outras pessoas encontrem novas peças e tentem novas combinações a partir do que já apresentamos. Isso é fundamental tanto para o sucesso da explicação de sistemas jurídicos existentes quanto para a construção de propostas sobre desenhos institucionais factíveis

Recebido para publicação em 19 de outubro de 2012 Aceito em 04 de novembro de 2012

\section{REFERÊNCIAS}

ALEXANDER L.; SHERWIN, E. The rule of rules: morality, rules, and the dilemmas of law. Durham; Londres: Duk University Press, 2001.

ALICKE, M. D. Culpable control and the psychology of blame. Psychological Bulletin, Berkeley, University of California, v.126, n.4, p.556-574, 2000.

AHARONI, E.; FRIDLUND, A. J. Punishment withou reason: isolating retribution in lay punishment of criminal offenders. Psychology, Public Policy, and Law. [S.1.], v.16, 2011. Advance online publication. Doi: 10.1037/ a0025821, 2011.

AUSTIN, J. The Province of jurisprudence determined Edinburgo: Cambridge University Press, [1832] 2001.

BENTHAM, J. An introduction to the principles of moral and legislation. In: TONRY, M. (Ed.) Why Punish? How Much? A reader on Punishment. New York: Oxford University Press, [1822] 2011. in determining punishment. Journal Experimental Social Psychology, New York, Elsevier, n.42, p.437-451, 2006.

CARLSMITH, K. M.; DARLEY, J. M. psychological aspects $\rightarrow$ of retributive justice. Advances of Experimental Social 2 Psychology, San Diego, Eksevier, v.40, p.193-236, 2008.

CARLSMITH, K. M.; DARLEY, J. M.; ROBINSON, P. H Why do we punish? Deterrence and just deserts as motives for punishment. Journal of Personality and Socia Psychology, Princeton, University of Princeton, v.83,n.2, p. 284-299, 2002.

CUSHMAN, F. The functional design of punishment and the psychology of learning. In: JOYCE, K. R.; STERELNY, B.; CALCOTT,B. Fraser (Ed.) Signaling, commitment and emotion, Cambridge: Psychological and Environmental Foundations of Cooperation. MIT Press, 2012. v.2. no prelo.

Crime and punishment: distinguishing the roles of causal and intentional analyses in moral judgment.Cognition Cambridge, v.108, n.2, p.353-380, 2008 .

; DREBER, A.; WANG, Y.; COSTA, J. Accidental outcomes guide punishment in a 'trembling hand' game. PLOS One, [S.1.], Yale University, v. 4, n.8, 2009 Doi:6610.1371/ journal.pone.0006699, 2009.

DANZINGER, S.; LEVAV, J.; AVNAIM-PESSO, L. Extraneous factors in judicial decisions. PNAS , Boston, Broad Institut, v.108, n.17, p.6889-6892, apr., 2011.

DARLEY, J. M. Morality in the law: the psychological foundations of citizens' desires to punish transgressions. Annual Review Law and Social Science, Toronto, v.5, p.1-23, 2009. DE QUERVAIN, D.; FISCHBACHER, U. TREYER, V.; SCHELLHAMMER, M.; SCHNYDER, U. et al. The neural basis of altruistic punishment. Science, v.305, n.5688, p.1254-1258, aug., 2004.

FEHR, E.; GÄCHTER, S. Altruistic punishment in humans. Nature, n.415, p.137-140, 2002.

FLANAGAN, O. Varieties of moral personality: ethics and psychological realism. Cambridge: Harvard University Press, 1991.

FULLER, L. The morality of law. New Haven: Yale University Press, 1969.

GNEEZY, U.; RUSTICHINI, A. A fine is a price. Journal of Legal Studies, Chicago, v.29, n.1, jan. 2000.

GÜRERK, Ö.; IRLENBUSCH, B.; ROCKENBACH, B. The competitive advantages of sanctioning institutions. Science,n.312, p.108-111, apr. 2006.

HART, H. L. A. The concept of law. Oxford: Clarendon Press, 1998.

KANT, I. The penal law and the law of pardon. In: TONRY, M. (Ed.) Why punish? How much? A reader on punishment New York: Oxford University Press, [1798] 2011.

. The philosophy of law - an exposition of the fundamental principles of jurisprudence as the schence of right. Edinburgo: T. \& T. Clark, [1887] 2010.

KNOBE, J. Answer to five questions. In: AGUILAR, J.; BUCKAREFF, A. (Ed.) Philosophy of action: 5 questions. London: Automatic Press, 2009

GÜRERK, Ö.; IRLENBUSCH, B.; ROCKENBACH, $\bar{B}$. The competitive advantages of sanctioning institutions. Science, n.312, p.190-194, 2006.

MASCLET, D.; NOUSSAIR, S.; VILLEVAL, T.; VILLEVAL M. Monetary and non- monetary punishment in the voluntary contributions mechanism. American Economic Review, [S.l.], AEA, v.93, n.1, p.366-380, 2003

NADELHOFFER, T. Maus atos, agentes culpáveis e ações intencionais: alguns problemas para a imparcialidade do júri. In: STRUCHINER, N. et al. (Ed.) Ética e realidade atual: implicações da abordagem experimental. Rio de Janeiro: PUC-Rio, 2011, p.61-94

SCHAUER, F. Playing by the rules: a philosophical examination of rule-based decision-making in law and in life. Oxford: Oxford University Press, 1998.

Thinking like a lawyer: a new introduction to legal reasoning. Cambridge: Harvard University Press, 2009.

SHEPPARD, B; CUSHMAN, F. Evaluating norms: an empirical analysis of the relationship between normcontent, operator, and charitable behavior. Vanderbilt Law Review, Columbia, v.63, n.1, p.55-109, 2009.

STRUCHINER, N. indeterminação e objetividade: quando o direito diz o que não queremos ouvir. In: MACEDO Jr, R.; BARBIERI, H. (Ed.) Direito e interpretação racionalidades e instituições. São Paulo: Saraiva, 2011.

O direito como um campo de escolhas: por uma leitura das regras prescritivas como relações. In RODRIGUEZ, J. et al. (Ed.) Nas fronteiras do formalismo. São Paulo: Saraiva, p.103-127, 2010. 
Para falar de regras - O positivismo conceitual como cenário para uma investigação filosófica acerca dos casos difíceis do Direito. 2005. Tese (Doutorado em Filosofia) - Programa de Pós-Graduação em Filosofia da PUC Rio. Rio de Janeiro, 2005. Disponível em: http:// ged1.capes.gov.br/CapesProcessos/919300-ARQ/919300 5.PDF.

SHECAIRA, F.A Distinção entre direito e moral e a distinção moral do direito. [S.l.s.n.] 2012. No prelo,

\section{SITES}

http://articles.latimes.com/2010/feb/10/local/la-me-pizzathief10$2010 f e b 10$ Acesso em: 02 out. 2012

http://socialistworker.org/2005-1/542/542 05 SantosReyes.shtml Acesso em: 02 out 2012

http://edition.cnn.com/US/Newsbriefs/9510/10-27/index.html Acesso em: 02 out. 2012

TAMANAHA, B. On the rule of law: history, politics, theory. Cambridge: Cambridge University Press, 2004

TONRY, M. Introduction: thinking about punishment In: (Ed.) Why punish? How much? A reader on punishment. New York: Oxford University Press, 2011. 


\section{PHILOSOPHICAL AND PSYCHOLOGICAL ASPECTS OF PUNISHMENTS: Gathering some Pieces of the Puzzle}

\author{
Noel Struchiner \\ Pedro H. V. Chrismann
}

The use of sanctions is a commonplace and it is usually associated with an expectation to increase the strength of a rule's normative force. Some experiments confirm this intuition and indicate that punishments make people cooperate more. Philosophers, however, debate without consensus on what should be the purpose of punishment. Despite the normative discussion, psychological studies show that ordinary people tend to make retributivist judgments. Moreover, psychology has pointed out some asymmetries in punitive behavior, such as the difference in people's standpoints when projecting norms and when they must apply the same norms; the influence of moral judgments in assigning intentionality in punitive judgments; and the perplexities involving punishment of accidents. The philosopher of law should aim at achieving an integrative view of the different information concerning punishment both to describe law more adequately and to construct a viable normative theory of law.

Keywords: Sanction. Punishment. Philosophy. Psychology. Law

\section{ASPECTS PHILOSOPHIQUES ET PSYCHOLOGIQUES DES SANCTIONS: réunissant quelques pièces du puzzle}

\author{
Noel Struchiner \\ Pedro H. V. Chrismann
}

Le recours à des sanctions est courant et généralement associé à une attente qui se veut d'augmenter la force normative des règles. Certaines expériences confirment cette intuition et indiquent que les punitions font en sorte que les personnes coopèrent plus. Les philosophes débattent cependant, sans en arriver à un consensus, sur les propos des punitions. En dépit d'un débat normatif, des études psychologiques démontrent que, dans leur jugement, les personnes communes ont une tendance punitive capable de rétribution. De plus, la psychologie nous rend attentifs à certaines asymétries dans le comportement punitif, comme la différence de préférences dans le choix des personnes pour la projection de normes et dans le jugement de celles-ci ; l'influence des jugements moraux dans l'attribution de l'intentionnalité pour les jugements punitifs et une certaine perplexité autour des accidents impliquant une punition. Le philosophe du droit devrait faire l'effort d'intégrer les différentes informations concernant les peines afin de fournir une explication plus adéquate du phénomène juridique et de construire des théories normatives plus réalisables.

Mots-ClÉs: sanction; punition; philosophie; psychologie; droit.

Noel Struchiner - Doutor em Filosofia. Professor do Departamento de Direito da Pontifícia Universidade Católica do Rio de Janeiro (PUC-Rio) e colaborador do Departamento de Filosofia da mesma Universidade. Tem experiência na área de Direito, com ênfase em Filosofia do Direito, atuando principalmente nos seguintes temas: filosofia da linguagem e direito, natureza das regras, modelos de tomada de decisão, desenhos institucionais, positivismo jurídico e filosofia experimental nas áreas de filosofia e psicologia moral. É Coordenador Adjunto do Projeto ERA (Ética e Realidade Atual), financiado pela FINEP, e do Centro de Ética da PUC-Rio (http://era.org.br/). Bolsista de produtividade em pesquisa (PQ) do CNPq e Jovem Cientista da FAPERJ. Publicações recentes: The cognitive psychology of the potentiality argument. American Journal of Bioethics, v. 13, p. 3638, 2013; A distinção entre direito e moral e a distinção moral do direito. RDE. Revista de Direito do Estado, v. 22, p. 131-145, 2012; Ética e realidade atual. Coletânea de Artigos. 1. ed. Rio de Janeiro: PoD, 2013.

Pedro H. V. Chrismann - Mestrando do Programa de Pós-Graduação em Direito da PUC-Rio. Graduado em direito pela Universidade Federal do Rio de Janeiro. Bolsista FAPERJ. Membro do Núcleo de Estudos sobre razão, direito e sentimentos morais do CNPq. 